\title{
On the Performance of Trimetazidine and Vitamin $E$ as Pharmacoprotection Agents in Cyclosporin A-Induced Toxicity
}

\author{
De la Cruz Rodríguez Lilia Cristina, ${ }^{1}$ Rey María del Rosario, ${ }^{2}$ \\ Araujo Carmen Rosa, ${ }^{1}$ and Oldano Ana Veronica ${ }^{2}$ \\ ${ }^{1}$ Clinical Biochemistry III, Instituto de Bioquímica Clínica, Facultad de Bioquímica Química y Farmacia, \\ Universidad Nacional de Tucumán, Balcarce 747, Tucumán, 4000 San Miguel de Tucumán, Argentina \\ ${ }^{2}$ Instituto de Bioquímica Clínica, Facultad de Bioquímica Química y Farmacia, Universidad Nacional de Tucumán, Balcarce 747, \\ Tucumán, 4000 San Miguel de Tucumán, Argentina
}

Correspondence should be addressed to De la Cruz Rodríguez Lilia Cristina; cdantur@fbqf.unt.edu.ar

Received 26 December 2012; Accepted 17 January 2013

Academic Editors: G. M. Campo, G. Edwards, and B.-N. Wu

Copyright (C) 2013 De la Cruz Rodríguez Lilia Cristina et al. This is an open access article distributed under the Creative Commons Attribution License, which permits unrestricted use, distribution, and reproduction in any medium, provided the original work is properly cited.

\begin{abstract}
The immunosuppressant drug cyclosporin $\mathrm{A}(\mathrm{CyA})$ has been used in diseases with immunological basis and in transplant patients. Nephrotoxicity and hepatotoxicity are the main adverse effects of this drug. To find a protective drug against those effects we assayed the cardioprotector Trimetazidine (TMZ) and vitamin E, used as nutritional supplements to alleviate oxidative stress. Six groups of eight male Wistar rats each were prepared (groups A-F): A, control; B, vitamin E (10 mg/Kg/day); C, TMZ (20 mg/Kg/day); $\mathrm{D}, 25 \mathrm{mg} / \mathrm{Kg} /$ day CyA; E, CyA and vitamin E $(25 \mathrm{mg} / \mathrm{Kg} /$ day CyA + $10 \mathrm{mg} / \mathrm{Kg} /$ day Vit E); F, TMZ for 20 days $(20 \mathrm{mg} / \mathrm{kg} / \mathrm{day})$; and then CyA $(25 \mathrm{mg} / \mathrm{kg} /$ day $)$ and TMZ $(20 \mathrm{mg} / \mathrm{Kg} / \mathrm{day})$. The experiment lasted 120 days. The exposure of rats to CyA promoted nephrotoxicity and hepatotoxicity with an increase in serum urea, creatinine, and glutamate dehydrogenase (GLDH). Structural and ultrastructural studies of liver and kidney were performed. Group D showed adverse effects induced by CyA since statistically significant differences were found with respect to the control group (A). Vitamin E (E) showed no protective effect. Pretreatment with TMZ (F) attenuated the adverse effects of CyA. We conclude that CyA-induced nephrotoxicity and hepatotoxicity are attenuated by the cytoprotective effect of TMZ. TMZ inhibits the reabsorption and, consequently, the accumulation of CyA in the cell. The antioxidant capacity of vitamin E did not improve the effect of CyA.
\end{abstract}

\section{Introduction}

Cyclosporin A (CyA) is a cyclic undecapeptide with strong immunosuppressive activity, since it has a specific inhibitory effect on the T-cell receptor signal transduction pathway [1, 2]. Reactive oxygen species (ROS) have been implicated in the nephrotoxicity and hepatotoxicity caused by CyA, either by direct action or by the activation of lipid peroxidation (LP) [3-6].

Our previous work showed that the effect of CyA on the antioxidant defense system (ADS) is related to lipoperoxidation and liver function. The results for the chronic and acute treatment, only with $20 \mathrm{mg} / \mathrm{Kg} / \mathrm{day}$ of CyA, caused alterations in liver parenchyma histoarchitecture [7]. In previous works we showed that CyA administration to organ transplant patients caused an increase in the levels of serum creatinine and urinary excretion of gamma-glutamyl transpeptidase (uGGT). These functional changes were dose and time dependent, showing structural alterations with doses higher than $15 \mathrm{mg} / \mathrm{Kg} /$ day CyA in chronic treatments [8]. Morphofunctional alterations in the liver parenchyma were observed in rats treated with $\mathrm{CyA}$ at different doses for 120 days. Doses higher than $15 \mathrm{mg} / \mathrm{Kg} /$ day CyA, equivalent to concentrations in blood of $437 \pm 13.40 \mathrm{ng} / \mathrm{mL}$ or greater, caused functional alterations in complexes I and II of the mitochondrial respiratory chain in the liver of treated rats [9].

In an attempt to design and develop therapeutic strategies that could prove effective against the adverse effects induced by $\mathrm{CyA}$, some investigators explored the protective role of antioxidants [10]. Vitamin E (Vit E) is the collective name 
for a group of liposoluble compounds derived from tocol and tocotrienol, alpha tocopherol being the one with greatest biological activity. Its absorption and distribution are closely related to the digestion, absorption, and distribution of lipids, the liver being its main storage organ, from where it is rapidly mobilized. The characteristic of "biological antioxidant" of Vit E derives from its molecular structure as its capability of fixing ROS types $\mathrm{O}_{2}{ }^{-}, \mathrm{O}_{2}{ }^{2-}$, and $\mathrm{OH}^{-}[11,12]$. Vitamin $\mathrm{E}$ prevents oxidation of polyunsaturated fatty acids and lipoproteins and it has been shown that the antioxidant effect of Vit E might be beneficial in the prevention of autoimmune, inflammatory and infectious diseases as well as neoplasia [1315].

Trimetazidine (TMZ), 1-2,3,4 trimetoxibencil piperazine, is a drug used as a cardioprotector since it prevents the secondary cell death that usually follows transient myocardial ischemia [16]. TMZ is a cytoprotector whose place of action and the mechanism and chronological order of its effects are not yet known in depth. According to some authors, TMZ acts at the mitochondrial level diminishing the betaoxidation of fatty acids. Another beneficial effect described in the existing literature is the attenuation of intracellular changes of sodium and hydrogen ions. Numerous studies have analyzed the protective effect of TMZ against myocardial ischemia-reperfusion injury in different models. Among the mechanisms suggested, the following have been mentioned as the most probable: hemodynamic changes, reduction in ROS toxicity, decrease in the inflammatory reaction, optimization of the energetic metabolism, and reduction in the utilization of fatty acids in favor of carbohydrates [17-20].

Our experiments using an in vivo model to study the effect of TMZ on the nephrotoxicity induced by gentamicin demonstrated that TMZ, when used in a 7-day pretreatment, was able to attenuate the nephrotoxic effect of this aminoglycoside [21].

To find a protective drug against the toxicity induced by CyA during chronic treatment, we assayed the cardioprotector Trimetazidine (TMZ) and vitamin E, used as nutritional supplements to alleviate oxidative stress.

\section{Materials and Methods}

2.1. Animals and Drugs. The experiments were performed with adult male Wistar rats of 180 to $200 \mathrm{~g}$ body weight housed in standard cages with a $12 \mathrm{~h}$ light-dark cycle (light on at 7:00 a.m.) at $20^{\circ} \mathrm{C}$ and $60 \%$ humidity. The animals were given a standard diet for rodents and tap water.

All experimental procedures complied with the regulations of the European Union (86/60/EEC) and with the recommendations of the Federación de Sociedades Sudamericanas de la Ciencia de Animales de Laboratorio-FESSCAL (Federation of South American Societies of Laboratory Animal Science).

(i) In the treatment of the animals the following drugs were used: CyA provided by Sandoz Laboratories (Germany) Sandimmune.

(ii) Vitamin E provided by Raymos Laboratories, Tanvimil E $400 \mathrm{mg}$. (iii) Trimetazidine provided by Servier Laboratories, Vastarel $20 \mathrm{mg}$.

2.2. Experimental Design. The animals were randomly divided into six groups $(n=8)$. The groups were treated according to the following schedule.

(i) Group A (control): animals were fed a standard ratmouse chow for 120 days.

(ii) Group B (control Vit E): animals were fed a standard rat-mouse chow supplemented with $10 \mathrm{mg} / \mathrm{Kg} /$ day Vit E for 120 days.

(iii) Group C (TMZ control): animals were fed a standard rat-mouse chow supplemented with $20 \mathrm{mg} / \mathrm{Kg} /$ day TMZ for 120 days.

(iv) Group D (CyA control): animals were fed a standard rat-mouse chow supplemented with $25 \mathrm{mg} / \mathrm{Kg} /$ day CyA, the drug being orally administered for 120 days.

(v) Group E (CyA + Vit E): animals were fed a standard rat-mouse chow treated with $25 \mathrm{mg} / \mathrm{Kg} /$ day CyA and $10 \mathrm{mg} / \mathrm{Kg} /$ day Vit E, the drugs being orally administered for 120 days.

(vi) Group F (CyA + TMZ): animals were fed a standard rat-mouse chow pretreated with $20 \mathrm{mg} / \mathrm{Kg} /$ day TMZ for 20 days and then treated with $20 \mathrm{mg} / \mathrm{Kg} /$ day TMZ and $25 \mathrm{mg} / \mathrm{Kg} /$ day CyA for 120 subsequent days.

During the chronic experiment, the animals were studied with daily evaluations of behavior, appetite, and activity.

The body weight of the animals was determined at three points in time: the beginning of the experiment, 60 days after the beginning, and 120 days after the beginning. At the end of the experiment, the liver and kidney were excised and weighed.

2.3. Samples. At the beginning and at the end of the experiment, blood samples were collected by tail vein punction and by intracardiac punction, respectively, for the biochemical studies.

2.4. Methods. The nitrogen compounds in blood, urea, and creatinine were determined using the urease method and Jaffe's colorimetric method, respectively. The reactives were provided by Wiener Laboratories [22, 23].

In blood samples, serum aminotransferases and glutamate dehydrogenase were determined using optimized UV methods [24, 25].

2.5. Histological Study. At the end of the experimental design, the animals were decapitated without previous sedation. Then they were bled and their liver and kidneys were removed and prepared for structural and ultrastructural studies.

Small portions of the kidney and liver previously separated were washed with physiological solution, fixed in a $10 \%$ formaldehyde solution, and embedded in paraffin. They were 
cut into 4-5 $\mu \mathrm{m}$ thick sections and stained with hematoxylineosin [26]. The histological slices were observed under an Axiostar plus Zeiss optical microscope.

For observation under the electron microscope, the liver and kidney portions were processed as follows: they were fixed in a $3.5 \%$ glutaraldehyde solution in $0.1 \mathrm{M}$ phosphate buffer at $\mathrm{pH} 7.40$ for $3 \mathrm{~h}$ and then placed in $1 \%$ osmium tetroxide. Then, the samples were treated with an aqueous solution of $2 \%$ uranyl acetate for $40 \mathrm{~min}$. After fixation, the tissues were gradually dehydrated by a successive passage through a series of increasing alcohol concentrations. Finally, they were passed through ketone and embedded in resin. Ultrathin sections were treated with uranyl acetate, placed in citrate, and examined at $50 \mathrm{kV}$ with a Zeiss EM 109 transmission electron microscope belonging to LAMENOA Electron Microscopy Laboratory of Northwestern Argentina [27].

2.6. Statistical Analysis. Analysis of variance and later comparison of means were performed with Tukey's test (alpha = $5 \%)$.

\section{Results}

During the 120-day chronic assay, the animals in the different groups increased their weight and maintained their healthy status. None of them died during the treatment.

Hepatosomatic ratio was determined at the end of the treatment, after the animals had been sacrificed. No significant differences were found in groups B, C, or F with respect to control group A. Groups D and E showed a statistically significant decrease in the hepatosomatic ratio with respect to control group A. These results are shown in Table 1.

Figure 1 shows the statistically significant increase in the activity of mitochondrial enzymes AST and GLDH. This increase was observed after chronic treatment with $25 \mathrm{mg} / \mathrm{Kg} /$ day CyA.

These biochemical findings show the experimental nephrotoxicity and hepatotoxicity induced by CyA. Group F, pretreated for 20 days with TMZ and then for 120 days with $\mathrm{TMZ}+\mathrm{CyA}$, showed a protective effect on the liver profile, with enzymatic activity of AST and GLDH comparable to that in control group A. However, the therapeutic scheme applied to group E reflected a behavior similar to group D. Vitamin $\mathrm{E}$, in these conditions, did no exert a hepatoprotective effect. In order to relate the biochemical changes observed to the histoarchitecture of the liver parenchyma, we studied histological slices with Mallory and hematoxylin-eosin staining of the liver parenchyma.

In Figure 2(a), 10x magnification shows hepatocytes in cords disposition around the central vein. They present a homogeneous cytoplasm with a central nucleus, with no cytological alterations.

In Figures 2(b) and 2(c), (20x) control groups: B with Vitamin $\mathrm{E}$ and $\mathrm{C}$ with $\mathrm{TMZ}$, respectively, shows liver parenchyma histoarchitecture with no alterations. In Figure 2(d) (20x) shows the histological slice of the liver parenchyma of group $\mathrm{D}$, treated with $25 \mathrm{mg} / \mathrm{Kg} /$ day CyA
TABLE 1: Hepatosomatic ratio in the treated groups.

\begin{tabular}{lc}
\hline Group & Hepatosomic ratio \\
\hline A (control) & $3.62 \pm 0.06$ \\
B (control Vit E) & $3.22 \pm 0.08$ \\
C (control TMZ) & $3.50 \pm 0.08$ \\
D (CyA) & $2.25 \pm 0.05$ \\
E (Vit E + CyA) & $2.30 \pm 0.06$ \\
F (TMZ + CyA) & $3.28 \pm 0.08$ \\
\hline
\end{tabular}

Hepatosomic ratio: (liver weight $\times 100)$ /total body weight.

for 120 days. We can see the central vein and the infiltration of mononuclear elements in the perivascular space. In Figure 2(e) (20x) shows the histological slice of the liver parenchyma of group E, treated with $25 \mathrm{mg} \mathrm{CyA} / \mathrm{Kg} /$ day and $10 \mathrm{mg}$ Vit E/Kg/day for 120 days. We can see mononuclear infiltrates in the whole liver parenchyma, including the portal spaces.

In Figure 2(f) (40x) shows the protective effect on liver parenchyma of pretreatment with TMZ for 20 days and then for 120 days with $20 \mathrm{mg} \mathrm{TMZ} / \mathrm{Kg} /$ day $+25 \mathrm{mg} \mathrm{CyA} / \mathrm{Kg} /$ day. We can see the conserved liver parenchyma histoarchitecture, similar to the one in animals control group A.

Portions of the liver were processed for ultrastructural observation, especially of the mitochondria.

Figure 3 shows the electron microphotograph of hepatocytes of the different treated groups with $82.640 \mathrm{x}$ magnification.

Figure 3(a) corresponds to control group A. We can see a hepatocyte with its nucleus with lax chromatin. At the top a mitochondria with normal size and structure can be observed in a transverse section. The intramitochondrial crests can be clearly seen $(7800 x)$.

Figure 3(b) shows the electron microphotograph of a hepatocyte from group D. The animals treated with $25 \mathrm{mg}$ CyA/Kg/day for 120 days show swollen mitochondria with destruction of the inner membrane and of their intramitochondrial crests, where enzyme complexes I and II are located (82.640x).

Figure 3(c) shows the electron microphotograph of a hepatocyte from group $\mathrm{F}$. The animals pretreated with $20 \mathrm{mg}$ of TMZ and then with $20 \mathrm{mg}$ TMZ/Kg/day + $25 \mathrm{mg}$ CyA/Kg/day for 120 days show conserved mitochondrial ultrastructure. Intramitochondrial crests can be observed (82.640x).

The renoprotective effect was studied. Figure 4 shows a statistically significant increase in the levels of serum urea and creatinine in animals from groups $\mathrm{D}$ (AvsD). These biochemical findings show the experimental nephrotoxicity induced by the treatment with CyA at a dose of $25 \mathrm{mg} / \mathrm{Kg} /$ day.

The therapeutic scheme used with group $\mathrm{F}$ (pretreatment with $20 \mathrm{mg} \mathrm{TMZ} / \mathrm{Kg} /$ day and simultaneous treatment with $20 \mathrm{mg}$ TMZ/Kg/day + 25 mg CyA/Kg/day) did not show significant biochemical changes (AvsF), showing the protector effect of TMZ on the renal function.

The nitrogen compounds urea and creatinine in group $\mathrm{E}$ were within the ranges of group $\mathrm{D}$. Vit $\mathrm{E}$ in these conditions did not exert a renoprotective effect. 


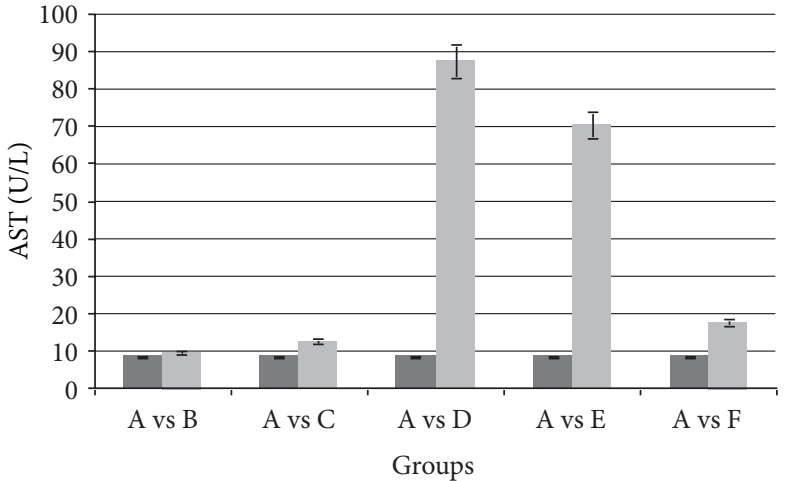

(a)

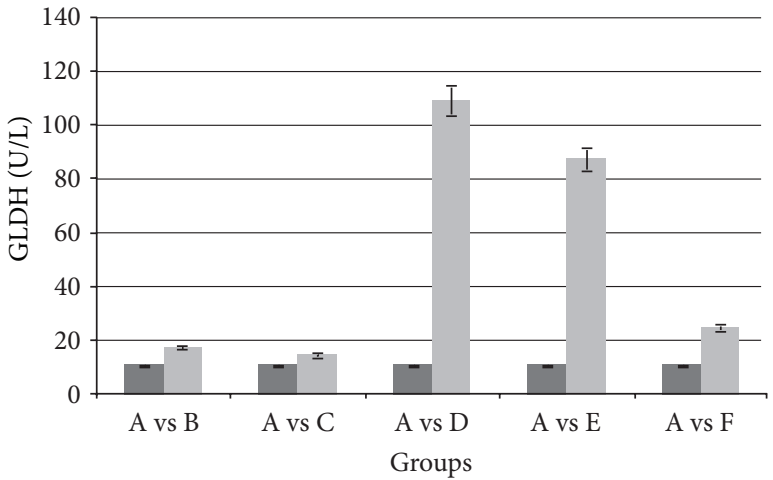

(b)

FIgURE 1: Serum AST and GLDH in treated animals compared with controls. Treatment with CyA $25 \mathrm{mg} / \mathrm{kg} / \mathrm{day}$ increased AST and GLDH activity (AvsB). The animals treated with Vit E $10 \mathrm{mg} / \mathrm{Kg} /$ day showed significant increases in GLDH and AST activity (AvsE). The animals pretreated with TMZ and TMZ + CyA showed no significant changes in this activity (AvsF). SD is shown at the top of each column.
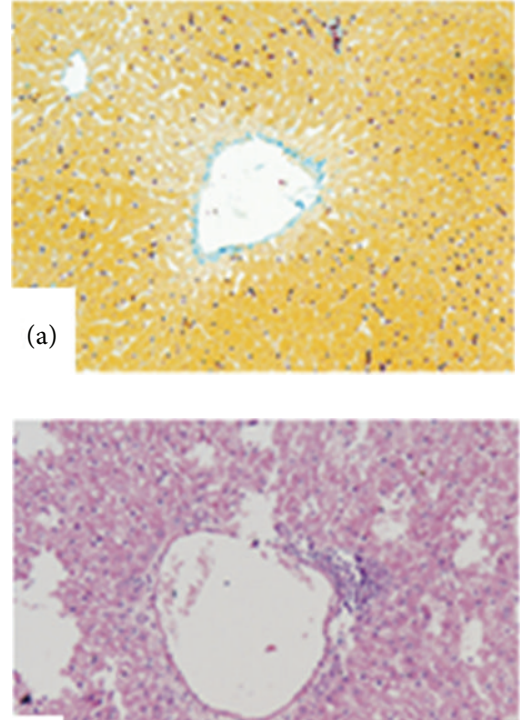

(d)

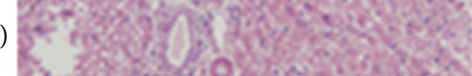

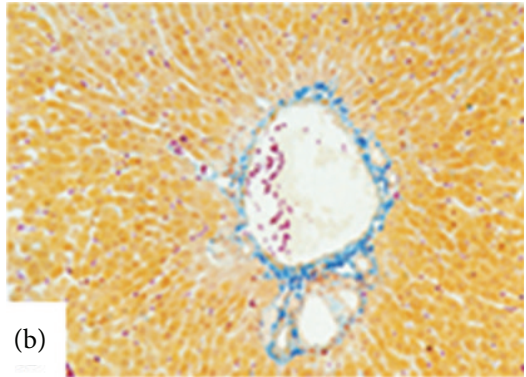
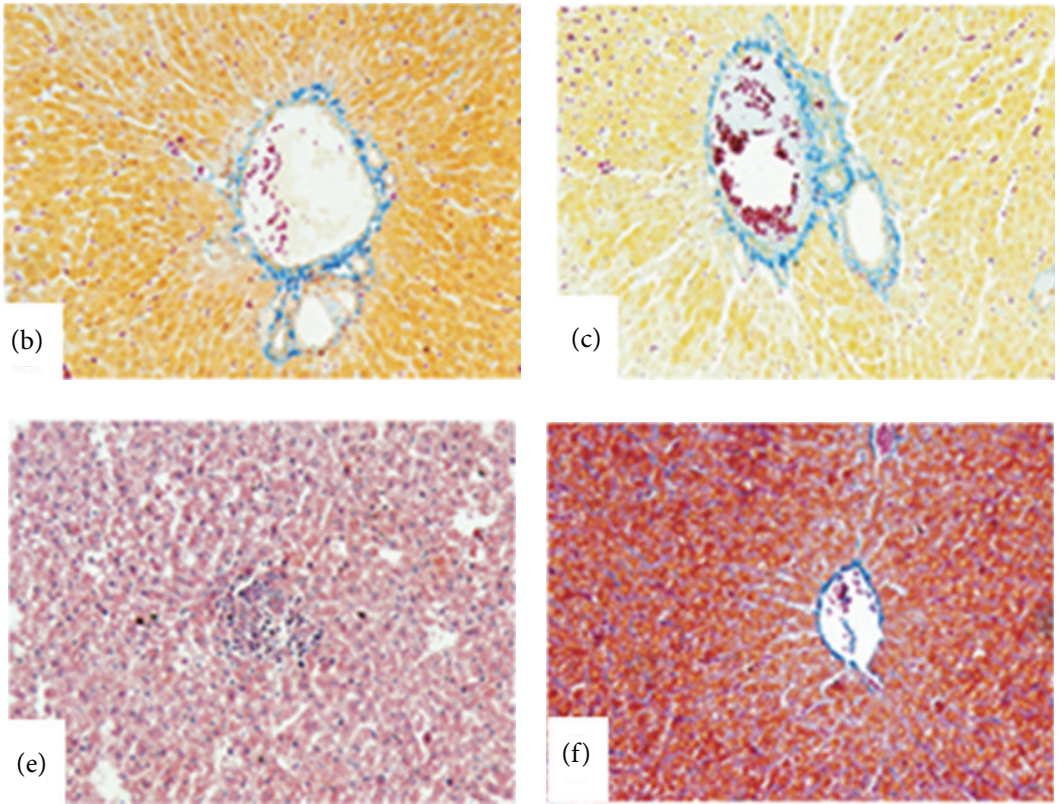

FIGURE 2: Histoarchitecture of the liver parenchyma. Hematoxylin-eosin (20x). (a) Control group A (10x). (b) Control group of treatment with vitamin E (40x). (c) Control group of treatment with Trimetazidine (40x). (d) Control group of treatment with $25 \mathrm{mg} / \mathrm{Kg} / \mathrm{day}$ of CyA (20x). (e) Group with synergistic treatment $10 \mathrm{mg}$ VitE/Kg/day $+25 \mathrm{mg} \mathrm{CyA} / \mathrm{Kg} / \mathrm{day}$ (20x). (f) Group pretreated with $20 \mathrm{mg}$ of TMZ and synergistic treatment with $20 \mathrm{mg} \mathrm{TMZ} / \mathrm{Kg} /$ day $+25 \mathrm{mg} \mathrm{CyA} / \mathrm{Kg} /$ day for 120 days (40x).

In both control and treated groups diuresis was measured for $24 \mathrm{~h}$, no statistically significant differences being found (data not shown). In order to compare the biochemical changes with the histoarchitecture of the renal parenchyma, histological slices of the kidney of rats from the different groups were studied. The following figures show these slices under optical and electron microscopes.

Figure 5 shows histological slices with Mallory staining of the renal parenchyma.

Figure 5(a) shows the kidney of a rat from control group A (10x). The renal cortex with a central glomerulus can be seen as well as a well-defined Bowman's space. The rest of the parenchyma shows transverse sections of proximal and distal convolute tubules.

Figure 5(b) shows a histological slice of group B (20x). Kidney of rat was treated with $10 \mathrm{mg}$ VitE/Kg/day. Part of a conserved glomerulus can be seen; however, in the tubular epithelium can be seen cell desquamation and hydropic degeneration corresponding to revertible dysplasia.

Figure 5(c) shows the kidney of a rat treated with $20 \mathrm{mg}$ TMZ/Kg/day (20x). The renal cortex with conserved glomerulus and tubules can be seen. Figure 5(d) corresponds to the kidney of a rat treated with $25 \mathrm{mg} \mathrm{CyA} / \mathrm{kg} /$ day (20x). In the renal medulla can be seen an interstitial fibrous. 


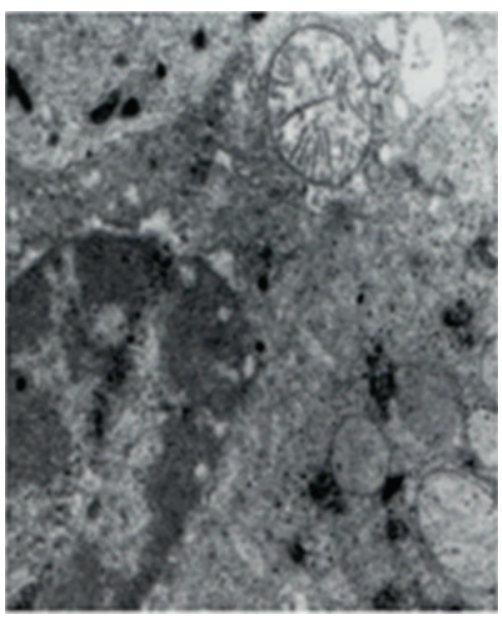

(a)

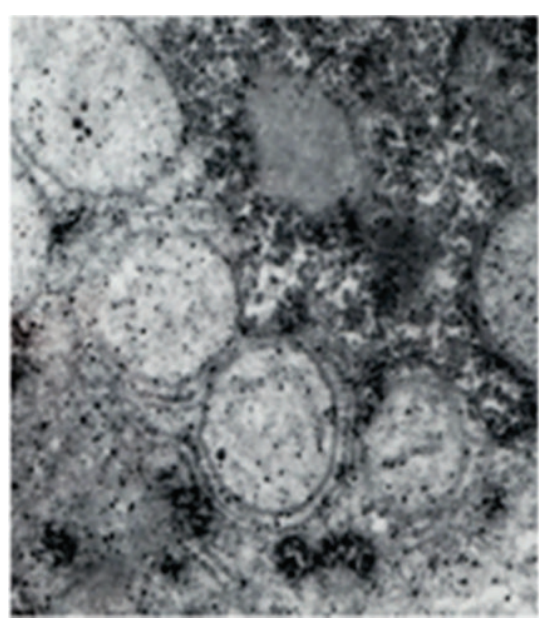

(b)

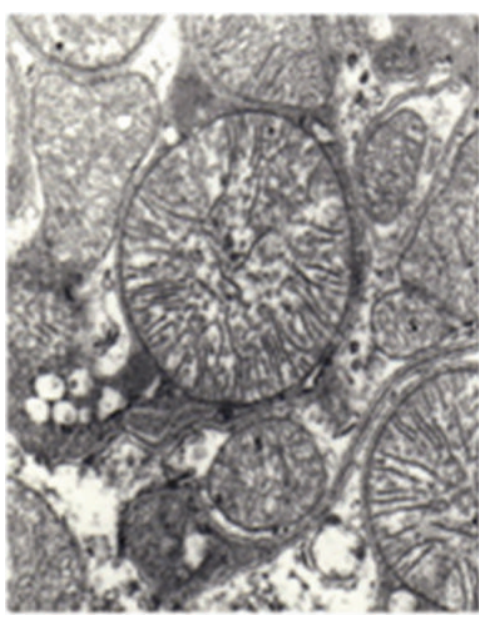

(c)

FIGURE 3: Ultrastructure of hepatocytes of the different groups. (a) Control group A (7800x). (b) Control group of treatment with $25 \mathrm{mg} / \mathrm{Kg}$ /day of CyA (82.640x). (c) Group pretreated with $20 \mathrm{mg}$ of TMZ and synergistic treatment with $20 \mathrm{mg} \mathrm{TMZ} / \mathrm{Kg} / \mathrm{day}+25 \mathrm{mg}$ $\mathrm{CyA} / \mathrm{Kg} /$ day for 120 days $(82.640 \mathrm{x})$.

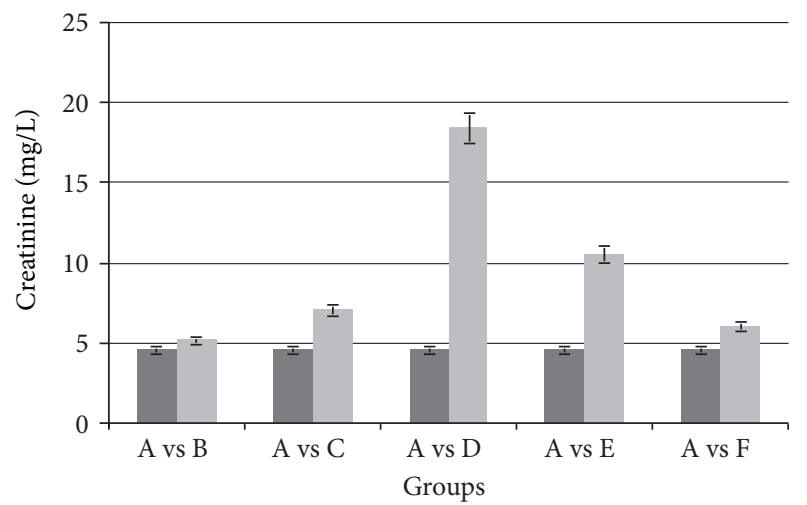

(a)

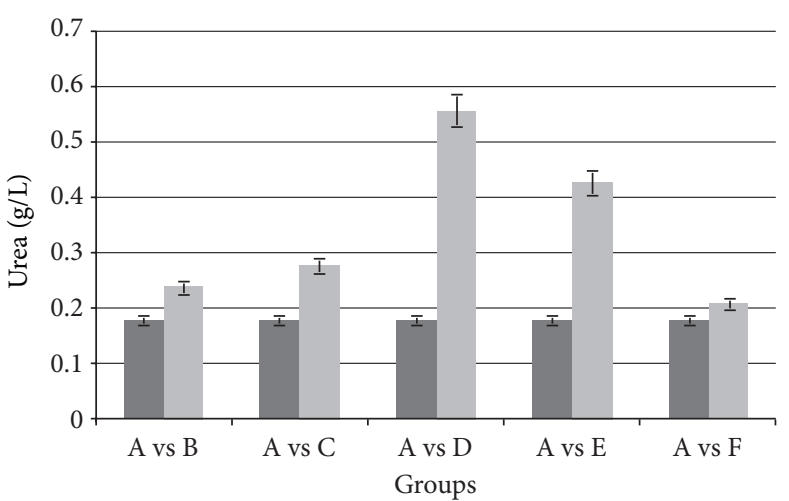

(b)

FIGURE 4: Serum urea in treated animals compared with controls. Animals treated with $25 \mathrm{mg}$ CyA/kg/day show a significant increase in urea and creatinine (AvsD). Group E shows a behavior similar to group D (AvsE). Pretreatment with TMZ and then with TMZ + CyA show the protective effect of TMZ on the renal function (AvsF). SD at the top of the columns.

Figure 5(f) shows the kidney of a rat pretreated with $20 \mathrm{mg} \mathrm{TMZ} / \mathrm{kg} /$ day and then with $20 \mathrm{mg} \mathrm{TMZ} / \mathrm{Kg} /$ day + $25 \mathrm{mg}$ CyA/Kg/day belonging to group $\mathrm{F}$ (10x). The renal cortex with glomeruli and a transverse slice of the conserved tubules can be seen, showing the protector effect of TMZ on the renal parenchyma.

However, the therapeutic scheme applied to group E reflected a behavior similar to group $\mathrm{D}$. Vit $\mathrm{E}$ in these conditions did not exert a renoprotective effect (Figure 5(e)).

Sections of the kidney were processed for ultrastructural observation, especially of the mitochondria.

Figure 6 shows the ultrastructure of transverse slices of proximal convoluted tubules.

Figure 6(a) shows the normal ultrastructure of the renal tubular epithelium of the male Wistar rats; can be seen cells with apical pole showing brush border conserved. In the apical brush border, can be seen the microvilli typical of the proximal tubular epithelium (7.800x).

Figure 6(b) shows the tubular epithelium of group D, treated with $25 \mathrm{mg} \mathrm{CyA} / \mathrm{Kg} /$ day. In the transverse section of the epithelium can be seen a tubular cell with intact basement membrane and atrophied apical border, and next cell without nucleus. Both cells show disarranged mitochondria, corresponding to cytoplasmic vacuolization or hydropic degeneration (7.800x).

Figure 6(c) shows two tubular cells from group E, treated with $10 \mathrm{mg}$ VitE/Kg/day $+25 \mathrm{mg} \mathrm{CyA} / \mathrm{Kg} /$ day. Both cells have their respective nucleus and cytoplasms conserved. However, can be seen mitochondria with altered shapes, sizes, and arrangement in relation to the control group. On the upper right hand side we can see the apical border totally atrophied and with no microvilli (7.800x). 

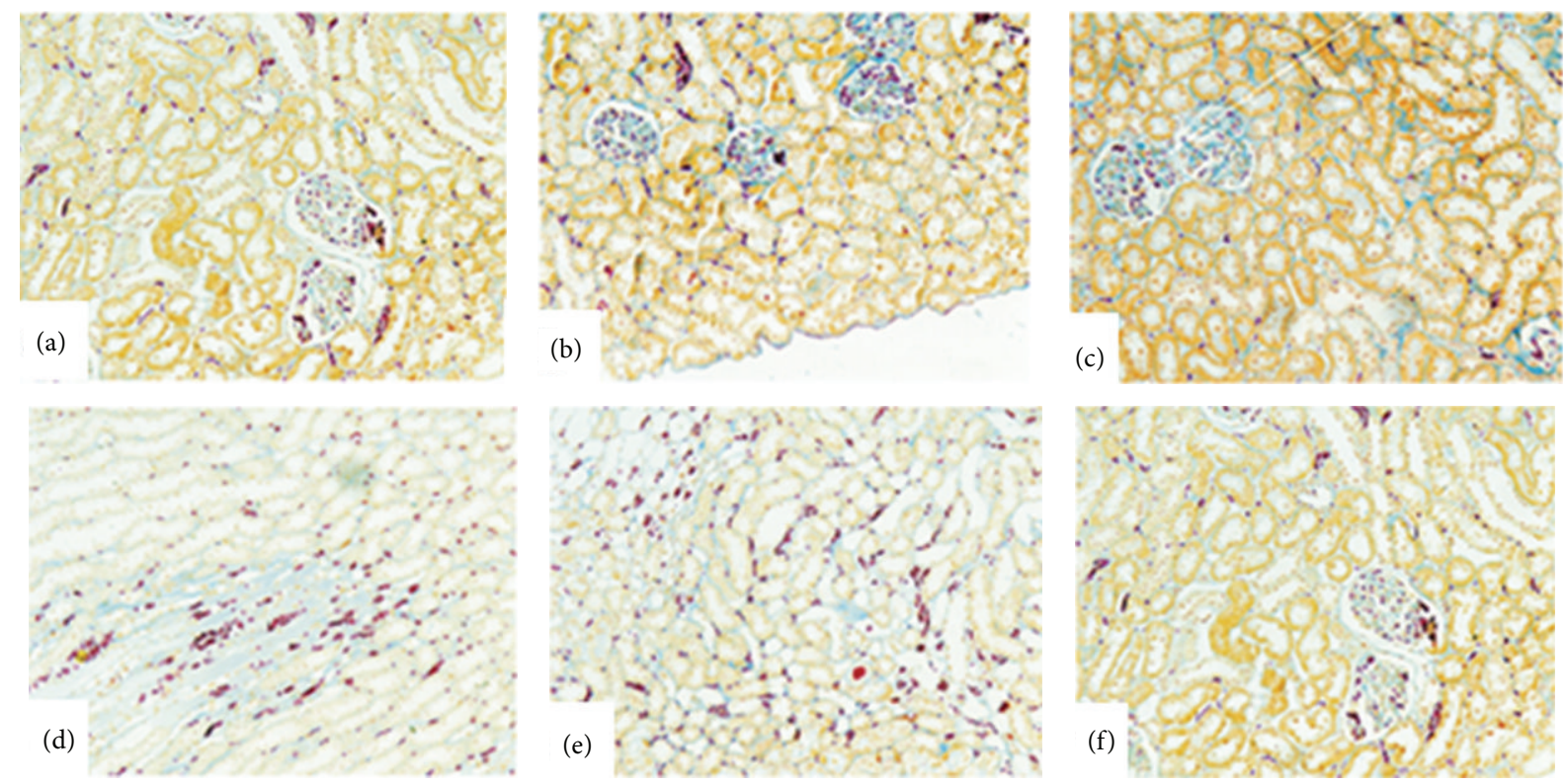

FIGURE 5: Histoarchitecture of the renal parenchyma. Hematoxylin-eosin (20x). (a) Control group A. (b) Control group of treatment with Vitamin E (20x). (c) Control group of treatment with Trimetazidine (20x). (d) Group with synergistic treatment $10 \mathrm{mg} V \mathrm{VitE} / \mathrm{Kg} / \mathrm{day}+25 \mathrm{mg}$ CyA/Kg/day (20x). (e) Group pretreated with $20 \mathrm{mg}$ of TMZ and synergistic treatment with $20 \mathrm{mg} \mathrm{TMZ} / \mathrm{Kg} / \mathrm{day}+25 \mathrm{mg} \mathrm{CyA} / \mathrm{Kg} / \mathrm{day}$ for 120 days $(20 \mathrm{x})$.

Figure 6(d) shows two nucleated tubular cells from group F, pretreated with $20 \mathrm{mg} \mathrm{TMZ} / \mathrm{Kg} /$ day and then with $20 \mathrm{mg}$ $\mathrm{TMZ} / \mathrm{Kg} /$ day $+25 \mathrm{mg}$ CyA/Kg/day. Can be seen the intact basement membrane with the perpendicular arrangement of the mitochondria at the basal domain.

\section{Discussion}

CyA is the drug most frequently used in transplant surgery because of its potent immunosuppressive action. However, its clinical use is accompanied by adverse side effects such as hypertension, nephrotoxicity, and hepatotoxicity. Previous studies established that ROS production and oxidative stress situation are involved in CyA cytotoxicity in cultured rat hepatocytes. In all cases, they attribute to CyA the ability to produce oxidative stress. However, none of them have explained what is the mechanism of formation and accumulation of ROS [11-15]. However, It has been demonstrated in numerous in vivo and in vitro experiments that CyAinduced renal failure and increased the synthesis of ROS, thromboxane, and lipid peroxidation products in the kidney $[28,29]$.

Different authors published works about the benefits of treatment with vitamin $\mathrm{E}$ to attenuate the nephrotoxic and hepatotoxic effects of CyA. Most of them have based their conclusions on the antioxidant capacity of alpha tocopherol. In a work published in 2007 [28, 29], oxidative stress and mitochondrial dysfunction were studied in tubular renal cells in vitro. The authors concluded that the cellular toxicity of CyA resulted from important alterations in the mitochondrial physiology and structure, with an increase in ROS synthesis and a decrease in antioxidant capacity.
Other authors have reported vitamin $\mathrm{E}$ as a protector against CyA-induced cytotoxicity in a rat hepatocyte culture $[30,31]$. One of those reports [30], with in vitro experiments, concluded that there is an imbalance in antioxidant enzymes due to the direct action of CyA on the primary hepatocyte culture and the fact that the simultaneous treatment with CyA and $V i t E$ reduces oxidative stress, inhibiting lipoperoxidation and restoring antioxidant enzymes.

In previous papers, we reproduced in animals the therapeutical schemes used with human transplant recipients. We have experimentally demonstrated that nephrotoxicity and hepatotoxicity are the main secondary effects of CyA treatment. These effects are time period and dose dependent [7-9].

For the purpose of finding a drug that would exert a protective effect against CyA-induced hepato- and nephrotoxicity, we assayed two drugs: vitamin E and TMZ.

We conclude that vitamin $\mathrm{E}$ does not exert a protector effect against CyA-induced nephrotoxicity. We base these results on the increased levels of serum urea and creatinine in group E, shown in Figure 4. These results correlate with our structural and ultrastructural findings (Figures 5(d) and 6(c)).

Special attention should be paid to the effect of treatment with $10 \mathrm{mg} / \mathrm{Kg} /$ day Vit E on group E. In Figure 5(b), we can see part of a conserved glomerulus and in the tubular epithelium cell desquamation and hydropic degeneration can be observed. These morphological changes correspond to regenerative dysplasia.

Apparently, Vit E by itself is capable of producing morphological changes in the tubular renal cell. Some authors have reported that when the optimal level $(80 \mu \mathrm{g} / \mathrm{dL})$ of this antioxidant is surpassed, the risks of toxicity increase [12]. 


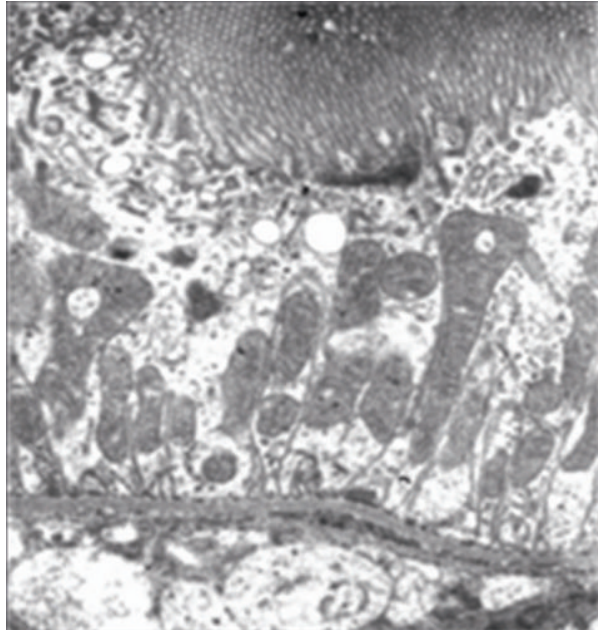

(a)

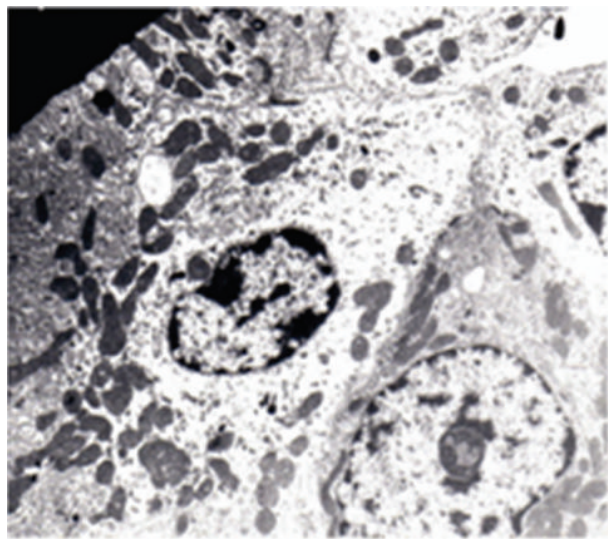

(c)

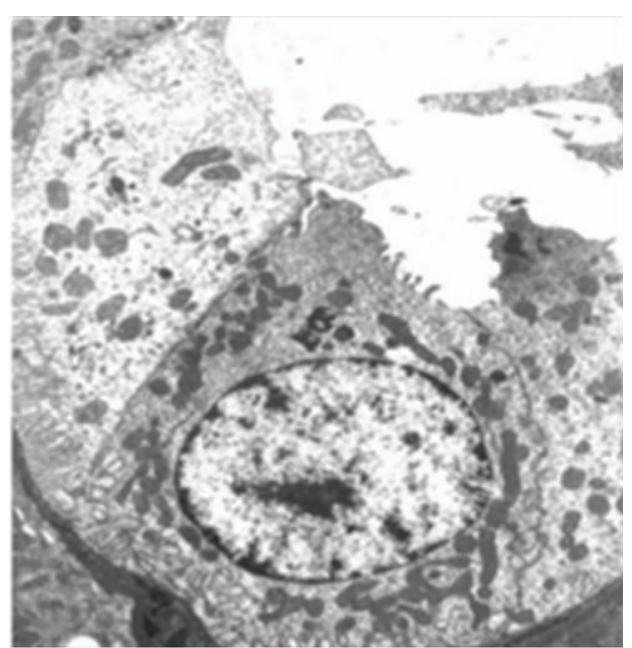

(b)

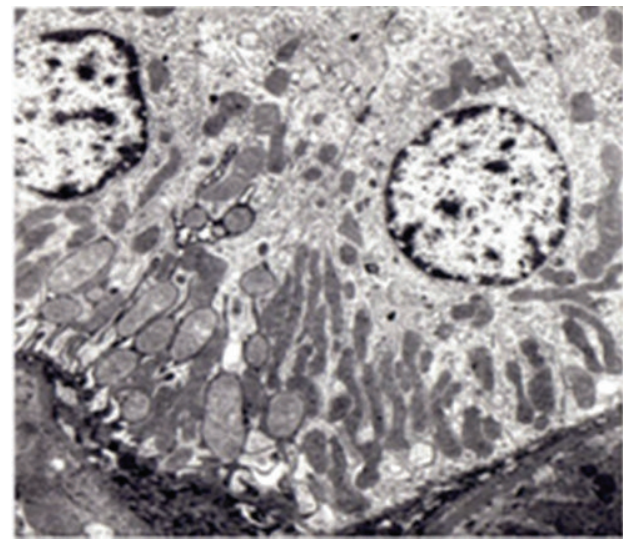

(d)

FIGURE 6: Ultrastructure of the tubule renal cell-proximal convolute tubule (7.800x): (a) Control group A. (b) Group D treated with 25 mg CyA/Kg/day for 120 days. (c) Group E with synergistic treatment $25 \mathrm{mg}$ CyA/Kg/day $+10 \mathrm{mg}$ Vitamin E. (d) Group F pretreated with $20 \mathrm{mg}$ of TMZ and synergistic treatment with $25 \mathrm{mg}$ CyA/Kg/day $+20 \mathrm{mg}$ of TMZ for 120 days.

On the other hand, the hepatotoxic effect of CyA is not attenuated by treatment with vitamin $\mathrm{E}$. If we analyze Table 1 , we can see that group E shows a statistically significant decrease in hepatosomatic ratio comparable only to group $\mathrm{D}$ with treatment with $25 \mathrm{mg} \mathrm{CyA} / \mathrm{Kg} /$ day. This decrease correlates with the increase in the activities of mitochondrial sublocalization enzymes: AST and GLDH, in Figure 1. The increase in AST and GLDH is statistically significant with respect to the other control and treated groups.

These results are corroborated by optical microscopy of the liver parenchyma in Figure 2(e). We can see infiltrates of mononuclear elements in the whole liver parenchyma, including the portal spaces, a similar histoarchitecture to the one described in group $\mathrm{D}$ treated with $25 \mathrm{mg} \mathrm{CyA} / \mathrm{Kg} /$ day. Figure 2(d).

To find a protective drug against those effects we assayed the cardioprotector Trimetazidine (TMZ). Some authors have reported that TMZ exerts a cytoprotective effect on the cardiomyocyte [16-20]. Our previous works have demonstrated the cytoprotection of TMZ in an in vivo model of gentamicininduced nephrotoxicity [21].
In the present work we studied and described the cytoprotective effect of TMZ against CyA-induced toxicity on the liver and kidney of treated rats. We demonstrated that pretreatment with $20 \mathrm{mg} / \mathrm{Kg} /$ day TMZ followed by treatment with $20 \mathrm{mg} / \mathrm{Kg} /$ day TMZ $+25 \mathrm{mg} / \mathrm{Kg} /$ day CyA for 120 days preserves the morphofunctionality of the tubular renal cell and of the liver cell. This was clearly manifested by the improvement in all the biochemical variables determining CyA-induced hepato- and nephrotoxicity (Figures 1 and 4).

These biochemical parameters correlate with the microand ultrastructural characteristics of the liver parenchyma. We can see histoarchitecture similar to the one in control group A (Figure 2(f)). Hepatocyte mitochondria ultrastructure of animals in group $\mathrm{F}$ appears conserved. We can see the intramitochondrial cristae, site of the mitochondrial respiratory chain (82.640x) Figure 3(c).

On the other hand, we demonstrated in an in vivo animal model to the mitochondria as a target for the toxic action of CyA. We reported that chronic treatment with CyA at doses above $15 \mathrm{mg} / \mathrm{Kg} /$ day causes alterations in the mitochondria, by the functional alteration in the mitochondrial respiratory 
chain in its complexes I and II, since this dose- and timedependent effect requires active cell metabolism [9].

In our study we investigated whether TMZ allows inhibition of the mitochondrial alteration induced by CyA. Trimetazidine protects the cells against the changes produced by the CyA-induced oxygen deficit. TMZ could offset ATP synthesis caused by the chronic administration of CyA. Trimetazidine optimizes the energetic metabolism of the ischemic cell through a metabolic exchange ("switch") between the fatty acid and glucose oxidation. In theory, TMZ would reduce strongly the fatty acid oxidation towards glucose, without affecting the mitochondrial respiratory chain efficiency. Furthermore, TMZ increases the production of phospholipids in the mitochondrial membranes, which confers stability to these structures.

We conclude the following.

(i) The target of the cytotoxic action of CyA is in enzymes of complexes I and II of the mitochondrial respiratory chain, which results in an alteration in the energy metabolism and leads to cell death by necrosis.

(ii) TMZ exerts a cytoprotective effect both on the liver cells and on the tubular renal cells. Among the different mechanisms of action proposed by some authors, pretreatment with TMZ would contribute to optimizing the energy metabolism of the mitochondria treated with TMZ + CyA at the doses and time periods studied.

(iii) Pretreatment with TMZ is essential for the protection of the cell since it confers stability and prevents the incorporation of $\mathrm{CyA}$ into the inner membrane of the mitochondria.

(iv) The antioxidant vitamin $\mathrm{E}$ does not exert a protective effect since we demonstrated that the CyA action in the mitochondrial chain does not involve ROS.

\section{Acknowledgments}

The authors acknowledge financial support from Secretaría de Ciencia y Técnica (Science and Technique Department) of the Universidad Nacinal de Tucumán under Grant no. CIUNT 26/D 422. They also acknowledge the assistance of Ms. Maria Agostina Potolicchio and César Sosa Padilla, PhD.

\section{References}

[1] S. Matsuda and S. Koyasu, "Mechanisms of action of cyclosporine," Immunopharmacology, vol. 47, no. 2-3, pp. 119-125, 2000.

[2] E. Toscano, J. Cotta, M. Robles, M. I. Lucena, and R. J. Andrade, "Toxicidad hepática inducida por los nuevos fármacos inmunosupresores," Gastroenterology and Hepatology, vol. 33, no. 1, pp. 54-65, 2010.

[3] G. Inselmann, H. U. Lawerenz, U. Nellessen, and H. T. Heidemann, "Enhancement of cyclosporin A induced hepato- and nephrotoxicity by glutathione depletion," European Journal of Clinical Investigation, vol. 24, no. 5, pp. 355-359, 1994.

[4] F. Serino, J. Grevel, K. L. Napoli, B. D. Kahan, and H. W. Strobel, "Oxygen radical formation by the cytochrome P450 system as a cellular mechanism for cyclosporine toxicity," Transplantation Proceedings, vol. 26, no. 5, pp. 2916-2917, 1994.

[5] I. Durak, M. Kacmaz, B. Cimen, S. Buyukkocak, S. Elagun, and S. Zturk, "The effect of cyclosporine on antioxidante enzyme activities and malondialdehide levels in rabbit hepatic tissues," Transplant Immunology, vol. 10, pp. 255-258, 2002.

[6] D. Andrés, N. Sanz, A. Zaragoza, A. M. Alvarez, and M. Cascales, "Changes in antioxidant defence systems induced by cyclosporine A in cultures of hepatocytes from 2- and 12month-old rats," Biochemical Pharmacology, vol. 59, no. 9, pp. 1091-1100, 2000.

[7] C. R. Araujo, S. E. Posleman, and L. C. De la Cruz Rodríguez, "Changes in the antioxidante defence system induced by Cyclosporin A," Acta Bioquímica Clínica Latinoamericana, vol. 41, no. 1, pp. 35-45, 2007.

[8] L. C. De la Cruz Rodríguez de Dantur, E. E. Del Sancio, S. E. Posleman, and cols, "Nefrotoxicidad por ciclosporina A evaluada mediante la gama glutamil transpeptidasa urinaria," Nefrología Latinoamericana, vol. 3, no. 4, pp. 300-305, 1996.

[9] L. C. De la Cruz Rodríguez, S. E. Posleman, C. R. Araujo, and R. Rey Mdel, "Hepatotoxic effect of cyclosporine A in the mitochondrial respiratory Chain," Journal of Applied Toxicology, vol. 26, pp. 310-317, 2007.

[10] R. Rezzani, "Exploring cyclosporine A-side effects and the protective role-played by antioxidants: the morphological and immunohistochemical studies," Histology and Histopathology, vol. 21, no. 1-3, pp. 301-316, 2006.

[11] L. A. Lexis, R. G. Fassett, and J. S. Coombes, " $\alpha$-tocopherol and $\alpha$-lipoic acid enhance the erythrocyte antioxidant defence in cyclosporine A-treated rats," Basic and Clinical Pharmacology and Toxicology, vol. 98, no. 1, pp. 68-73, 2006.

[12] G. De Arriba, J. P. Homedo, S. R. Rubio et al., "Vitamin E protects against the mitochondrial damage caused by cyclosporin A in LLC-PK1 cells," Toxicology and Applied Pharmacology, vol. 239, no. 3, pp. 241-250, 2009.

[13] T. Parra Cid, J. R. Conejo García, F. Carballo Álvarez, and G. De Arriba, "Antioxidant nutrients protect against cyclosporine A nephrotoxicity," Toxicology, vol. 189, no. 1-2, pp. 99-111, 2003.

[14] J. K. Jenkins, H. Huang, K. Ndebele, and A. K. Salahudeen, "Vitamin E inhibits renal mRNA expression of COX II, HO I, TGF $\beta$, and osteopontin in the rat model of cyclosporine nephrotoxicity," Transplantation, vol. 71, no. 2, pp. 331-334, 2001.

[15] Z. Mostafavi-pour, F. Zal, A. Monabati, and M. Vessal, "Protective effects of a combination of quercetin and vitamin $\mathrm{E}$ against cyclosporine A-induced oxidative stress and hepatotoxicity in rats," Hepatology Research, vol. 38, no. 4, pp. 385-392, 2008.

[16] P. F. Kantor, A. Lucien, R. Kozak, and G. D. Lopaschuk, "The antianginal drug trimetazidine shifts cardiac energy metabolism from fatty acid oxidation to glucose oxidation by inhibiting mitochondrial long- chain 3-ketoacyl coenzyme A thiolase," Circulation Research, vol. 86, no. 5, pp. 580-588, 2000.

[17] M. Marzilli, "Cardioprotective effects of trimetazidine: a review," Current Medical Research and Opinion, vol. 19, no. 7, pp. 661-672, 2003.

[18] P. Monteiro, A. I. Duarte, L. M. Gonçalves, A. Moreno, and L. A. Providência, "Protective effect of trimetazidine on myocardial mitochondrial function in an ex-vivo model of global myocardial ischemia," European Journal of Pharmacology, vol. 503, no. 1-3, pp. 123-128, 2004.

[19] A. Grymberg, "Effectors of fatty acid oxidation reduction: promisgin new anti-ischaemic agents," Current Pharmaceutical Design, vol. 11, pp. 489-509, 2005. 
[20] H. Kaur, S. S. V. Padi, and K. Chopra, "Attenuation of renal ischemia-reperfusion injury by trimetazidine: evidence of an in vivo antioxidant effect," Methods and Findings in Experimental and Clinical Pharmacology, vol. 25, no. 10, pp. 803-809, 2003.

[21] L. C. De la Cruz Rodríguez, C. R. Araujo, S. E. Posleman, and R. Rey Mdel, "Attenuation in gentamicina-induced neprhotoxicity: trimetazidine versus $\mathrm{N}$-acetyl cysteine," Journal of Applied Toxicology, vol. 30, pp. 343-353, 2010.

[22] J. K. Fawcet and J. E. Scott, "A rapid and precise method for the determination of urea," Journal of Clinical Pathology, vol. 13, no. 2, pp. 156-157, 1960.

[23] H. G. Biggs and J. M. Cooper, "An evaluation of tour methods of measuring urinary creatinine," Clinical Chemistry, vol. 7, no. 6, pp. 655-673, 1961.

[24] H. U. Bergmeyer, G. N. Bowers, M. Horder, and D. W. Moss, "Provisional recommendations on IFCC methods for the measurement of catalytic concentrations of enzymes. Part II. IFCC method for aspartate aminotransferase," Clinical Chemistry, vol. 23, no. 5, pp. 887-899, 1977.

[25] Deutsche Gesellschaft für Klinische Chemie, "Z. Clin Chem and Clin biochem," 12, 391, 1974.

[26] R. Martoja, M. Martoja-Pierson, and L. C. Grumbles, Técnicas De Histología Animal, Toray-Masson; S.A. Barcellona, 1970.

[27] L. Spannhof, Histoquímica Teórica Y Práctica, Acribia, Zaragoza, Spain, 1996.

[28] J. Pérez De Hornedo, G. De Arriba, M. Calvino, S. Benito, and T. Parra Cid, "Cyclosporin A causes oxidative stress and mitochondrial dysfunction in renal tubular cells," Nefrologia, vol. 27, no. 5, pp. 565-573, 2007.

[29] G. De arriba, J. P. De Hornedo, S. R. Rubio et al., "Vitamin E protects against the mitochondrial damge caused by cyclosporin A in LLC-PK1 cells," Toxicology and Applied Pharmacology, vol. 239, no. 3, pp. 241-250, 2009.

[30] J. Palomero, A. I. Galan, M. E. Munoz, M. J. Stump, J. GonzálezGallego, and R. Jimenez, "Effects of aging and cyclosporin treatment on the hepatobiliary efflux of glutathione," Life Sciences, vol. 73, pp. 3387-3397, 2003.

[31] Z. Mostafavi-Pour, F. Zal, M. Ahmad, and M. Vessal, "Protective effects of a combination of quercetin and vitamin $\mathrm{E}$ against cyclosporine A-induced hepatotoxicity in oxidative stress and rats," Hepatology Research, vol. 38, no. 4, pp. 385-392, 2008. 

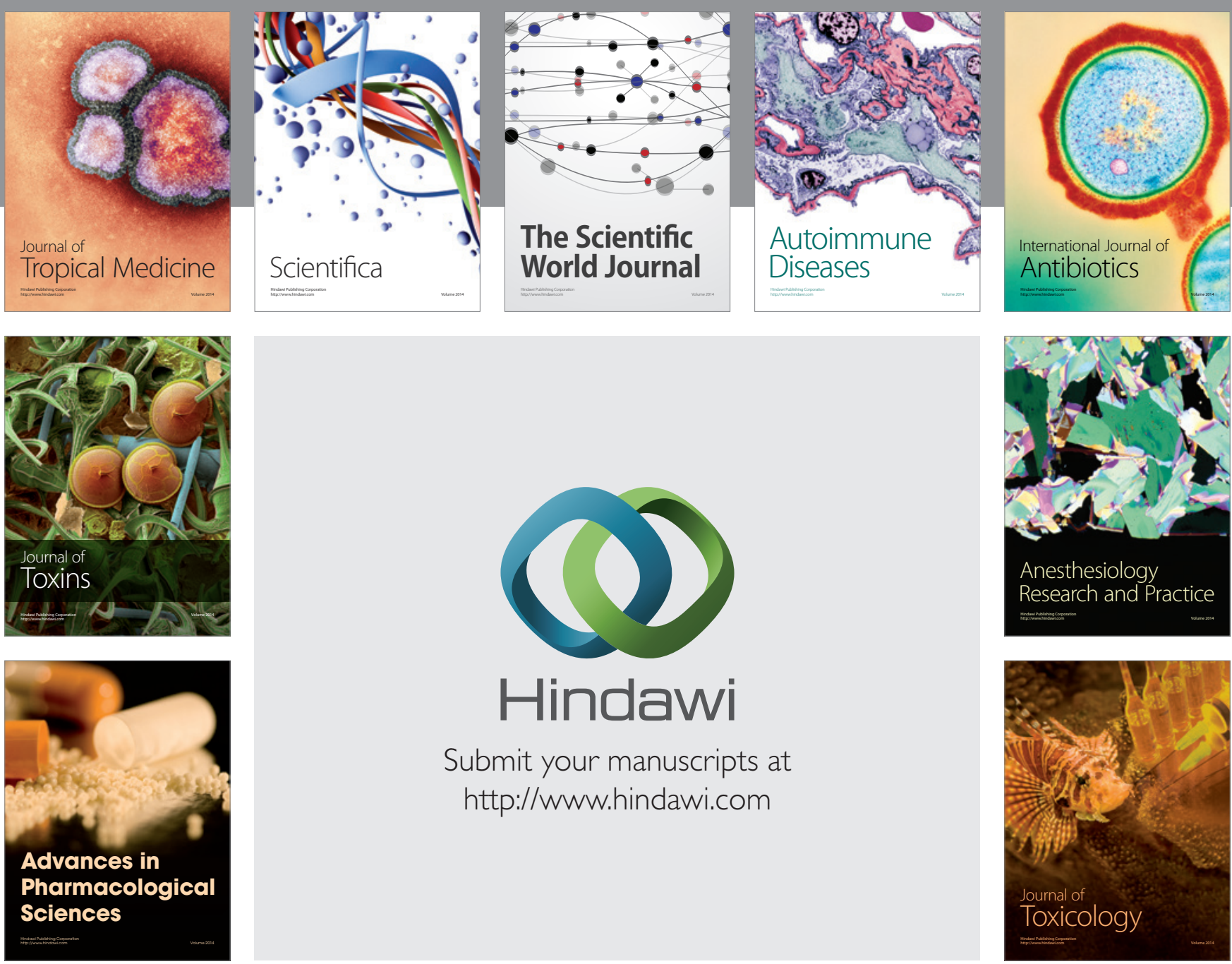

\section{Hindawi}

Submit your manuscripts at

http://www.hindawi.com
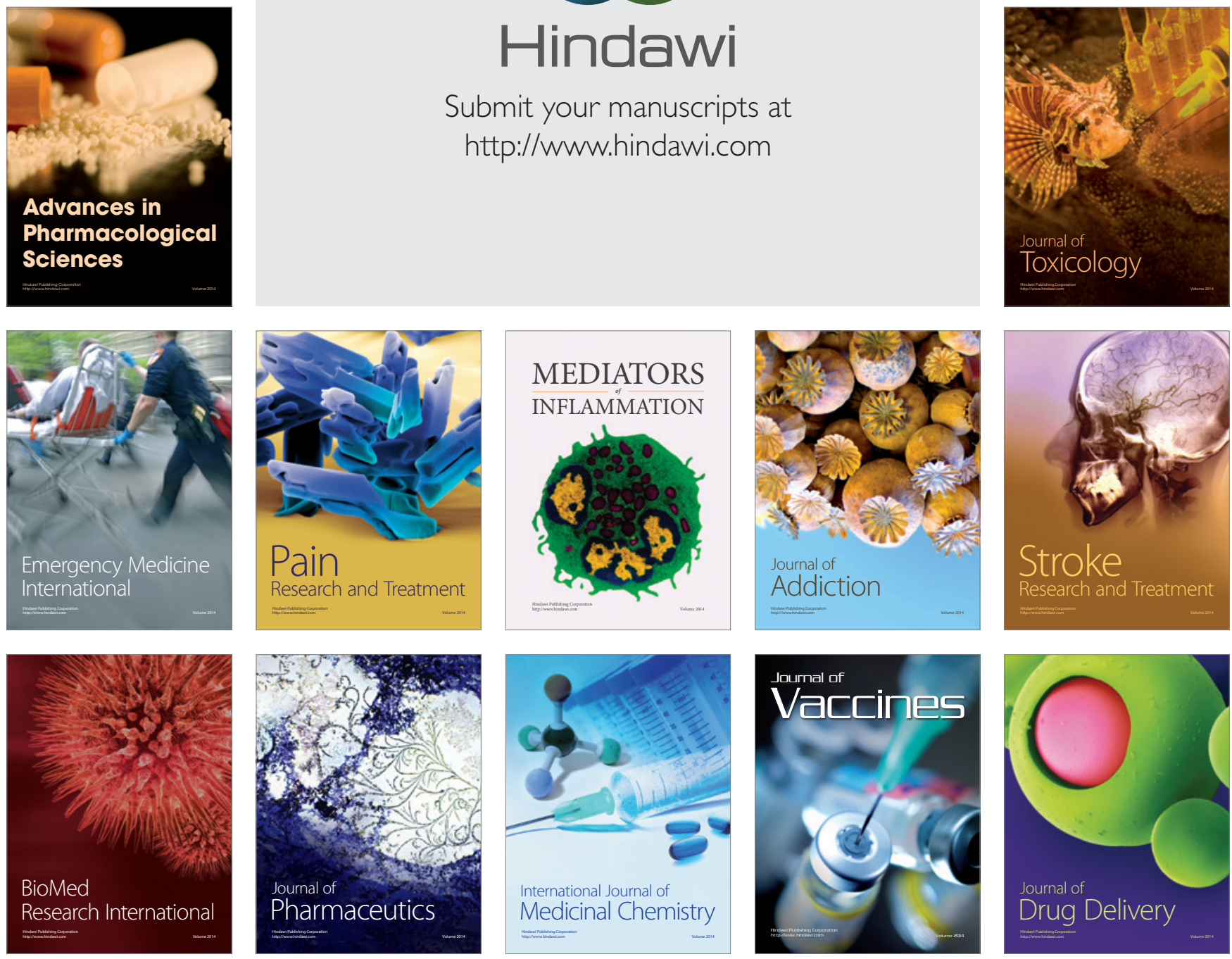